\title{
Strategies for Securing Energy Supply to High-Priority Buildings during Emergencies: With Emphasis on General Hospitals
}

\author{
Ji-Ae Lee ${ }^{1,}$ Won-Hwa Hong ${ }^{2 *}$ and Gyu-Yeob Jeon ${ }^{3}$ \\ ${ }^{1}$ School of Architecture Eng., Kyungpook National Univ., Republic of Korea \\ ${ }^{2}$ School of Architecture Eng., Kyungpook National Univ., Republic of Korea \\ ${ }^{3}$ School of Architecture Eng., Jeju National Univ., Republic of Korea \\ ${ }^{1}$ ize0304@naver.com, ${ }^{2}$ hongwh@knu.ac.kr, ${ }^{3}$ hi.gyuyeob@gmail.com
}

\begin{abstract}
The damages caused by natural disaster are unpredictable. It is almost out of control because its scale is entirely different from what we have experienced before. Natural disaster of climatic change is getting force. The effects of the disaster like flood block the energy supply route which is the municipal Lifeline. This is very dangerous and causes states of emergency. The blackout occurred in September 2011 showed that it causes extensive damage to the whole society. Especially important facilities like hospitals even suffer worse situations which cause casualty. This study examined, through field investigation, the actual conditions of large general hospitals' energy consumption and the status on their establishment of emergency power systems. Based on such investigation, analysis was made of the ways to establish emergency power systems capable of maintaining properly the functioning of hospital buildings and providing effective response during massive blackout.
\end{abstract}

Keywords: Blackout, High-Priority Buildings, Emergency power supply, Hospital buildings, Electric Load Model

\section{Introduction}

Each year, an explosive number of natural disasters are being reported from around the world which is associated with environmental pollution and climate change, and the resulting ramifications are reaching a proportion that could cause a national crisis. One such example from a close geographical region would be the 2011 massive earthquake that struck Tohoku, Japan, and the resulting Tsunami, which had not only left the area virtually unrecoverable but also caused the Fukushima nuclear plant's reactor to stop its operation. Having played a pivotal role in supplying massive quantities of energy to the country's south-central regions, the plant not operating drove the country to face a serious energy crisis. As illustrated in this example, excessive dependence on fossil fuels has led to massive emissions of $\mathrm{CO}_{2}$ which is associated with the greenhouse effect which in turn is contributing to the global warming and rapid changes in the global climate, causing abnormal weather phenomena around the Globe including earthquakes and floods. Literally, the entire Planet is undergoing more disasters and catastrophes each year than it had ever been before, with the disasters becoming larger in scale and their impact reaching more areas [11].

But the above-described natural disasters are not the only factor that is driving our society further into crisis. Our world is also being forced to deal with man-made, social disasters whose ramifications, unlike the unforeseeable natural disasters,' are becoming 
more serious as the human society continues to advance and creating more complex and diverse living environments.

Whilst our society is undergoing rapid economic development and the resulting energy resources depletion, spreading of the WTO system and energy market are changing the landscape of the energy industry significantly, the supply of energy/power is barely catching up with the increasing demands. Although this situation is being handled by supplying more renewable energy and more nuclear power, by connecting power grids between countries, etc., such countermeasures may not be swift enough in the case of sudden power supply crisis, and the ramifications could be pervasive. Hence, efforts are being made to come up with alternative measures that are pannational in nature.

In 2011, the 9.15 blackout that had dealt a significant blow to Korean society caused a paralysis in the circular functioning of Korea's energy-consuming networks as per the circular shut-down system in place at national levels, causing not only industrial entities to stop production but also hospitals, traffic systems and communication systems, too, to stop functioning. Even elevators in high-rise buildings had been deactivated due to the circular shut-down system. Literally, the entire Korean society had been deprived of its energy capability and functioning that depends on it. Unless Koreans collectively reduce their energy demands drastically as well as quickly, there is no knowing when and where such crisis will re-visit Korean society.

In cities where demands for energy are high and usable space is limited, the landscape is dotted with buildings and structures which play an important role and thus whose maintenance is absolutely crucial in sustaining urban living. Such buildings/structures play a particularly important role in times of crisis, including disasters and catastrophes.

Among those buildings/structures that sustain society with their multiple functions, hospitals are especially important because they are associated with saving human lives, hence they are not only significant but essential as well. Due to improvement in living standards and the growing supply of social welfare facilities among other reasons, hospitals demand energy relatively consistently both during weekdays and weekends, and their demand for electricity and/or heating is continuous. Such consistent and constant demand for energy sets hospitals apart from other types of buildings/structures in terms of energy consumption characteristics. Hence, it is imperative that those characteristics and importance associated with hospitals be made aware, and that appropriate systems and management strategies be reviewed for predicting damages due to disasters/catastrophes and for preparedness, damage identification and rescue capability.

In order to maintain the functioning of hospital buildings/structures in the event of disasters/catastrophes and to minimize the damages and respond efficiently, this paper attempted to (a) examine the current status on energy consumption by hospitals under normal circumstances and (b) come up with strategies for securing energy supply such that they serve as suitable countermeasures during emergencies. 


\section{Local and Overseas Case Studies and Korea's Emergency Power Failure Control}

\subsection{Case Studies of Domestic and Overseas Disasters and Catastrophes}

The recent frequent incidents of natural disasters being reported throughout the world are closely related to global warming and the resulting changes in climate, and the extent of such disasters is growing each year [12].

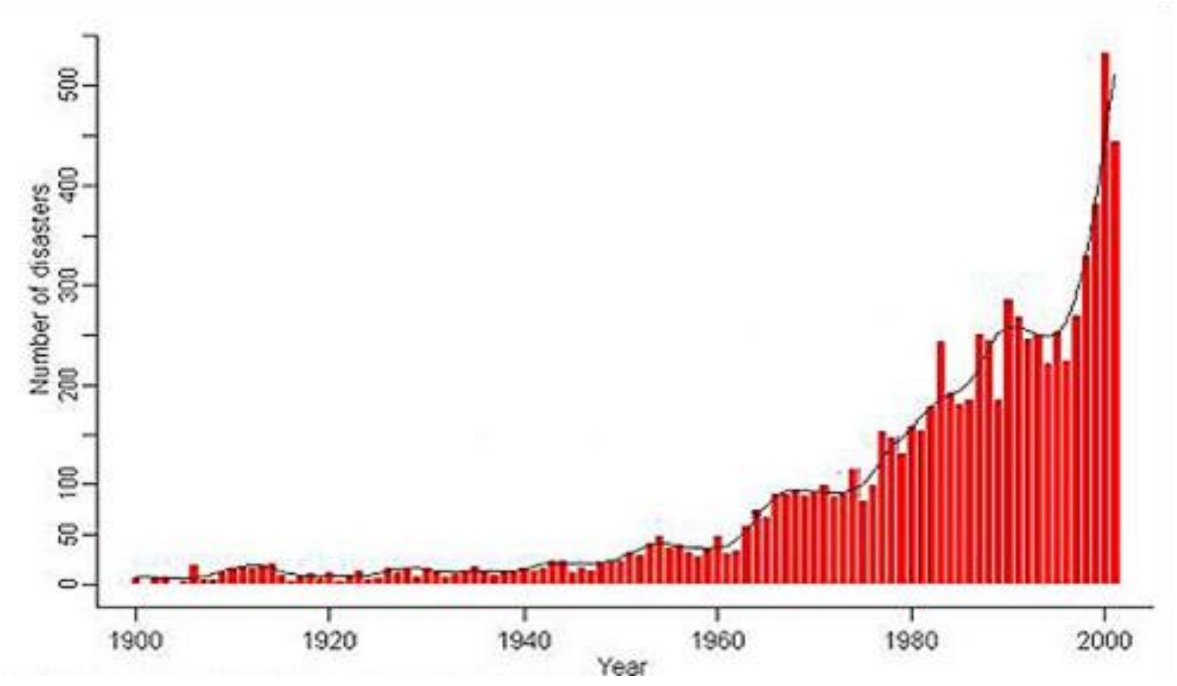

Figure 1. Damages Reported from Around the World Due to Disasters

Taiwan had undergone unprecedented power failures by the typhoons and the resulting heavy rainfalls on 29 July 1999 and the massive earthquake on 21 September of the same year, which disasters had caused the economy to lose at least $60 \%$ of its power supply. In Taiwan, demands for power are concentrated in north, whereas the massive power supplying source is located in the south-central part of the territory, which layout makes the grid network connecting north and south reach $345 \mathrm{kV}$, and the power lines linking the two regions are fed in dual schemes. Such grid design tends to make any power loss incident turn into a massive one as it did for the aforesaid incidents in 1999. The 1999 catastrophes served as an opportunity for Taiwan to launch a comprehensive review of its entire power transmission network and to start to plan on massive transmission facilities so as to be able to cope with the rapidly growing demands for power.

The massive California power failure incident was caused by the lack of power supply capability and the bottleneck phenomenon involving power transmission facilities. As the state had been under excessive environmental restrictions on power facilities and the NYMBY phenomenon which had led to restrictions in the construction of new power supply facilities and the state's lack of supply capability while its existing facilities were advancing in age, power was being imported from neighboring areas such as the State of Washington to meet the demands. But the neighboring states cut their supply because they were losing their own power-export capability due to increasing demands for power in their own territories. That cut in power supply had no doubt driven California to suffer from insufficient power supply. 
Another example in the United States: the massive blackout that occurred on 14 August 2003 in the northeastern part of the United States started as damages had occurred to three power lines located near Cleveland. The accident with the transmission lines caused system overload in nearby power facilities in about 10 seconds, which in 26 minutes led to the overheated transmission systems nearby, thus causing chain-reaction-like transmission line accidents thereafter. Less than one hour, eight states in North America were facing massive power loss.

Over in Europe, Italy is the country that shows the highest level of dependence on power import compared with its fellow European countries. Italian import of power from the Continent stands at about $17 \%$ against its total power demand. In 2003, power transmission lines in the area in Switzerland near Italian borders suffered breakage due to storms. The incident escalated to massive cutoff of power in all transmission lines that connect Italy to the remainder of Europe.

As for the Republic of Korea, the Typhoon Maemi in 2003 had caused power transmission line damages which led to the stoppage of operation in a total of eight power plants, causing power loss in approximately 1,480,000 households. The extent of that power outage had accumulated to about 3.8 million $\mathrm{kW}$, whose aftermath were rectified $100 \%$ in five days. Fortunately for Koreans, the timing had coincided with the country's Chuseok (Thanksgiving) holidays, during which the majority of the industries were celebrating the holidays and as a result the impact on production was minimal. Noteworthy is the flaw in the country's crisis management system that had been revealed especially by the government agencies located in the typhoon-affected areas which had failed to maintain their computer and communication systems leading to delays in casualty assessment and reporting. Those agencies, which became "victims" of their own defects, weren't even equipped with minimal levels of emergency power generators, hence they virtually failed to execute their crisis-management functioning at the earlier stages of power outage, which stages are the crucial timeframe in any crisis management situations. Another massive power loss incident had occurred on 15 September 2011, during which incident the country's national circular power shut-down system had led to massive paralysis not only in industrial production lines but also in hospitals and traffic systems as well as communication malfunctioning and stoppage in high-rise elevator operation. The impact on Korean society was massive as well as pervasive in that a paralysis was caused in every part of the society as its circular power-supply system failed to function.

\subsection{Korea's Emergency Power Loss Control and Response System}

In the Republic of Korea, supply of energy in between cities during emergencies is based on energy supply between regions as planned. Referring to a 2004 power exchange document, it is stated that a recovery plan is in place against power outage in the entire system such that the independent power generators are designated to ensure prompt system recovery during any failure or blackout in the power supply system according to the standards for power system reliability and electric quality maintenance, and that in times of emergency power outage, the power supply system recovery plan as stated in the emergency power outage response procedure will be established to ensure a stable and fast recovery system in place. The said recovery plan is stated such that during a wide-area power outage or an entire power system failure where independent power generators are designated and area/region-specific independent power generators are required, the procedure will be implemented separately for power training facilities, transmission businesses, and power generation businesses for the recovery of their 
systems. The recovery plan also specifies that independent power generators and generators for priority power supply be designated for each area/region such that service is provided by dividing into main line and reserve line for each area/region [5].

Roughly, the power outage confirmation procedures entail transmission businesses and generation businesses' notification of the incident to the power trading facility immediately following the incident, and the power trading facility's checking of the entire power supply shut-down status by collating the power supply information from automated supply facilities and auxiliary facilities and the system status information provided by power businesses [10]. In cases where such checking reveals the situation is indeed an entire system failure, the power trading facility must utilize its communication facilities to simultaneously summon transmission and generation businesses for each area/region and to notify them about the situation. However, if the communication facilities, too, have failed, the emergency power outage response procedure to be followed [4].

\section{Analysis of Types of High-Priority Buildings/Facilities during Emergencies}

\subsection{Definition of High-priority Buildings}

Important or high-priority buildings in cities refer to those equipped with facilities that are essential in maintaining cities and the social life associated with them. There are co-relations existing between high-priority buildings. Since damages to these buildings can soon lead to the spread of secondary damages or disasters, it is imperative that emergency response measures be provided considering a balance between the inter-dependence and independence of each high-priority building. Specific types of high-priority buildings are divided into the following[2]:

1) Information processing center: Specifically, the majority of this type includes office spaces (centers) and computer centers where extensive business places are mobilized to deliver real-time online processing of information using general-purpose computer systems.

2) Financial services industry: Refers to the "dealers," including financial institutes and similar establishments where currency bills, bonds, etc., are traded and business at international levels is carried out.

3) Social infrastructure: Refers to communication, water and sewage systems, transportation/transit services, and other elements that constitute social infrastructure.

4) Broadcasting centers: Refers to broadcasting stations that produce and transmit public TV and radio programs. The role played by these facilities is significant in that their failure to carry on their provision of information has huge impact on society which is particularly true during wide-area emergencies.

6) Newspapers and news agencies: The former where information editing, printing and issuing takes place and the latter where important sources of such information are found both play a crucial role in maintaining society.

7) Hospitals: These services wherein life-sustaining systems and important operating facilities are found play a particularly significant role due to its life-saving purposes. Hence, it is imperative to maintain the functioning of hospitals. 
8) Research institutes: Private as well as corporate research facilities are among high-priority buildings because of the importance of timing in long-term experiences, tests, etc., which, when discontinued by power failure, can cause massive losses in time and money.

\subsection{Surveys of function-specific Importance of high-priority Buildings}

The AHP (Analytic Hierarchy Process) analysis, which had been carried out as a pilot study to this paper, is divided into two types: (a) a survey of 10 experts, namely professional hospital facility managers, field operators of government/public agencies' disaster and urban affairs departments, fire services' prevention and administrative field operators, and other specialists closely associated with disasters/catastrophe and building function management and having expert knowledge in their chosen fields; and (b) an SPSS-based survey questionnaire given to 50 safety association trainees, the majority of whom being associated with construction, architecture and fire-fighting or with related fields.

The importance of each of the high-priority buildings that is borne during emergencies was assessed for priorities by comparing the values obtained from multiplying the weight given to each criterion by the weight given to each building use as stated in each alternative. Reviews of this analysis show that the said values are the sum of all multiplied values for all alternatives, and hence the comparative method is quantitative. Among the high-priority building categories, hospitals were found to be the most important building, only next to fire services and police departments. Figure 2 summarizes the results of AHP analysis on highpriority buildings [7].

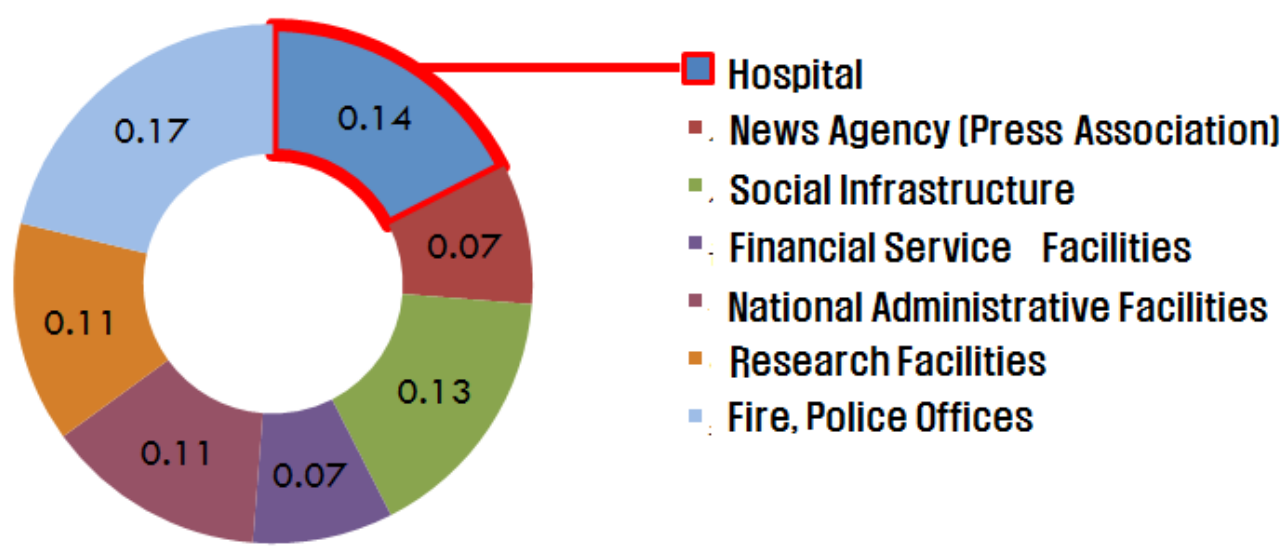

Figure 2. Surveys of High-Priority Buildings through AHP Analysis

\subsection{Definition and Type of High-priority Facilities}

The surveys of priority rank for each building facility revealed that priority was given to firefighting/safety related facilities, power supply facilities, communication systems, water supply and drain facilities, transportation/transit systems, HAVC systems, and heating facilities in this order. 
Figure 3 illustrates the priority analysis on building facilities during emergencies, i.e., importance of high-priority building services and architectural facilities functioning that is to maintain the functioning of cities [2].

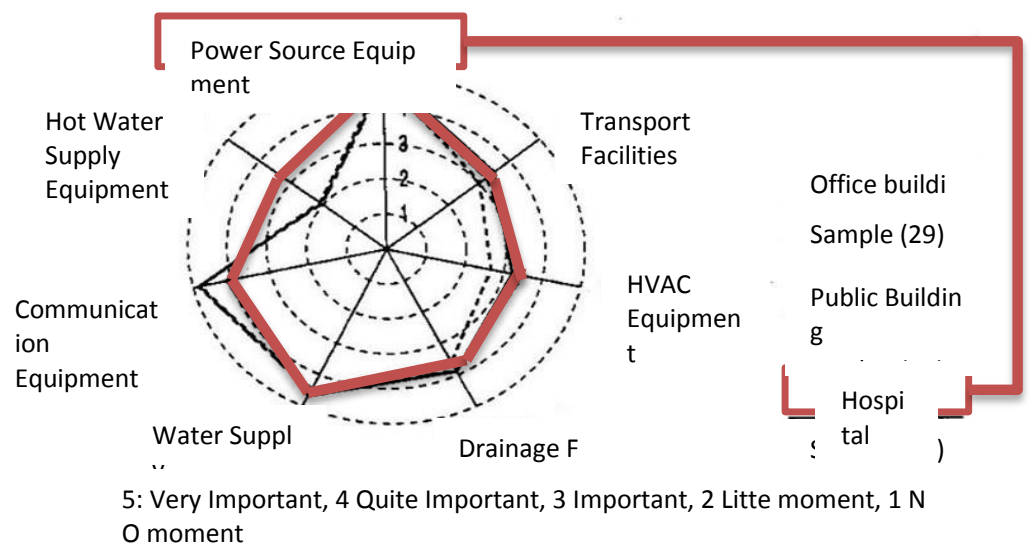

\section{Figure 3. Importance of Power Systems in Hospital Buildings During Emergency}

The analysis was done by the urban environment and planning lab at the Japanese Waseda University [3]. Like the pilot study, the surveys, too, showed relatively higher priority given to power facilities and communication systems. That the highest priority had been given to firefighting/safety related facilities and power supply facilities is reasonable considering emergency response situations, but the higher priority given to maintaining sufficient communication system functioning requires a review of the reason behind. Results of both the pilot study and the surveys revealed that not only the firefighting/safety related facilities but the power facilities and communication systems, too, are considered important parts of highpriority buildings during emergencies, hence it is imperative that their functioning be maintained.

As shown in Figure 3, power systems were found to be the most important facilities among the ones considered particularly important not only in hospitals but in major civic buildings as well.

Technology used in hospitals for treatment has progressed consistently, and various special electronic devices have been utilized for medical treatment. Such medical equipment does not allow even a momentary loss of power, and for that very reason, hospital buildings require greater reliability and safety of their power systems than other business buildings. Furthermore, due to a rapid increase in the use of medical equipment, fast propagation of office automation equipment, and a rise in the cooling load to create more hygienic environment, the consumption of electricity has increased rapidly [1].

Emergency power supply refers to the power supply unit that feeds electricity to firefighting facilities (pumps, emergency lighting, radios for rescue purposes, etc.,) in cases where normal power supply is interrupted due to fire, earthquake, or other unforeseen incidents [3].

Reserve power supply is defined as the normal power supply to be provided immediately following a power outage caused by lightning, accident/incident, etc., again in unexpected areas/locations such as office spaces and Internet server managing facilities, and specifically as the independent power generators and batteries used in times of normal power supply shutdown. Except for hospitals, reserve power is defined such that it should be able to maintain 
for 30 minutes the functioning of most high-priority buildings by converting within seconds to emergency/reserve power supply mode.

The above-said requirement notwithstanding, there are no previous studies done by Korean researchers on energy supply and management systems during emergencies and emergency/reserve power supply in cities during emergencies. Moreover, despite the utter importance of batteries (the most fundamental emergency power supply source), regulations specifying batteries have never been announced in Korea. Furthermore, the UPS units used in hospitals for precision machinery have never been subject to any specific local specifications, only being in line with the IEC standards [8]. Hence, to that end, surveys were carried out to find out the optimum no. of hours to be sustained by emergency/reserve power supply. The results showed that with hospitals, 50.7 hrs. on average, and with communication systems, $45.2 \mathrm{hrs}$. on average are the respective duration preferred by the respondents.

\section{Analysis of Status on Surveyed General Hospitals' Electrical Load and Emergency Power Systems}

\subsection{Status on Surveyed Hospitals}

For the purpose of this study, an investigation was made of 12 general hospitals located in Daegu Metropolitan City (Republic of Korea). Techniques utilized for the investigation were (a) interviews with the personnel in charge of the hospital facilities and (b) surveys of the said facilities. Among the 12 hospitals, the data from seven hospitals feasible for analysis were examined. Table 1 summarizes the surveyed hospitals' facilities and the status on their power systems.

Table 1. Summary of Surveyed Hospitals and Status on their Power Systems

\begin{tabular}{c|c|c|c|c|c|c|c}
\hline Hospital & Year & $\begin{array}{c}\text { Height of } \\
\text { Buildings }\end{array}$ & $\begin{array}{c}\text { Total } \\
\text { floor } \\
\text { aea }\left(\mathrm{m}^{2}\right)\end{array}$ & $\begin{array}{c}\text { Self-power } \\
\text { generation } \\
\text { system }\end{array}$ & $\begin{array}{c}\text { Storage } \\
\text { battery }\end{array}$ & $\begin{array}{c}\text { Backup } \\
\text { power } \\
\text { supply } \\
\text { system }\end{array}$ & UPS \\
\hline A & 1907 & 11 & 95642 & $12 \mathrm{~h} / 4163 \mathrm{KW}$ & - & $\begin{array}{c}2 \text { line } \\
\text { continue } \\
/ 8900 \mathrm{KW}\end{array}$ & $30 \mathrm{~m} / 1275 \mathrm{KVA}$ \\
\hline B & 1983 & 16 & 79000 & $15 \mathrm{~h} / 7900 \mathrm{KW}$ & $\begin{array}{c}6 \mathrm{~m} / 120 \mathrm{~V}- \\
200 \mathrm{AH}\end{array}$ & $\begin{array}{c}\text { Continue } \\
/ 9500 \mathrm{KW}\end{array}$ & $24 \mathrm{~m} / 450 \mathrm{KVA} * 5$ \\
\hline $\mathrm{C}$ & 1980 & 12 & 66965 & $6 \mathrm{~h} / 1135 \mathrm{KVA}$ & $10 \mathrm{~m} / 400 \mathrm{AH}$ & - & $30 \mathrm{~m} / 250 \mathrm{KVA}$ \\
\hline $\mathrm{D}$ & 1983 & 9 & 61799 & $10 \mathrm{~h} / 1750 \mathrm{KVA}$ & - & $\begin{array}{c}2 \text { line } \\
\text { continue } \\
/ 5100 \mathrm{KW}\end{array}$ & \\
\hline E & 2011 & 8 & 7436 & $24 \mathrm{~h} / 260 \mathrm{KW}$ & - & - & \\
\hline F & 1991 & 9 & 11946 & $4 \mathrm{~h} / 290 \mathrm{KW}$ & - & & \\
\hline G & 1999 & 14 & 80900 & None & & & \\
\hline
\end{tabular}


Results from the surveys show that the subjects (hospitals) had installed an emergency power system such that $33 \%$ of the subjects used only in-house generating systems and UPSs (Uninterrupted Power Systems), another 33\% of the subjects used inhouse generating systems and UPSs along with backup power supply systems, with other cases counting for the remaining subjects (i.e., 17\% each).

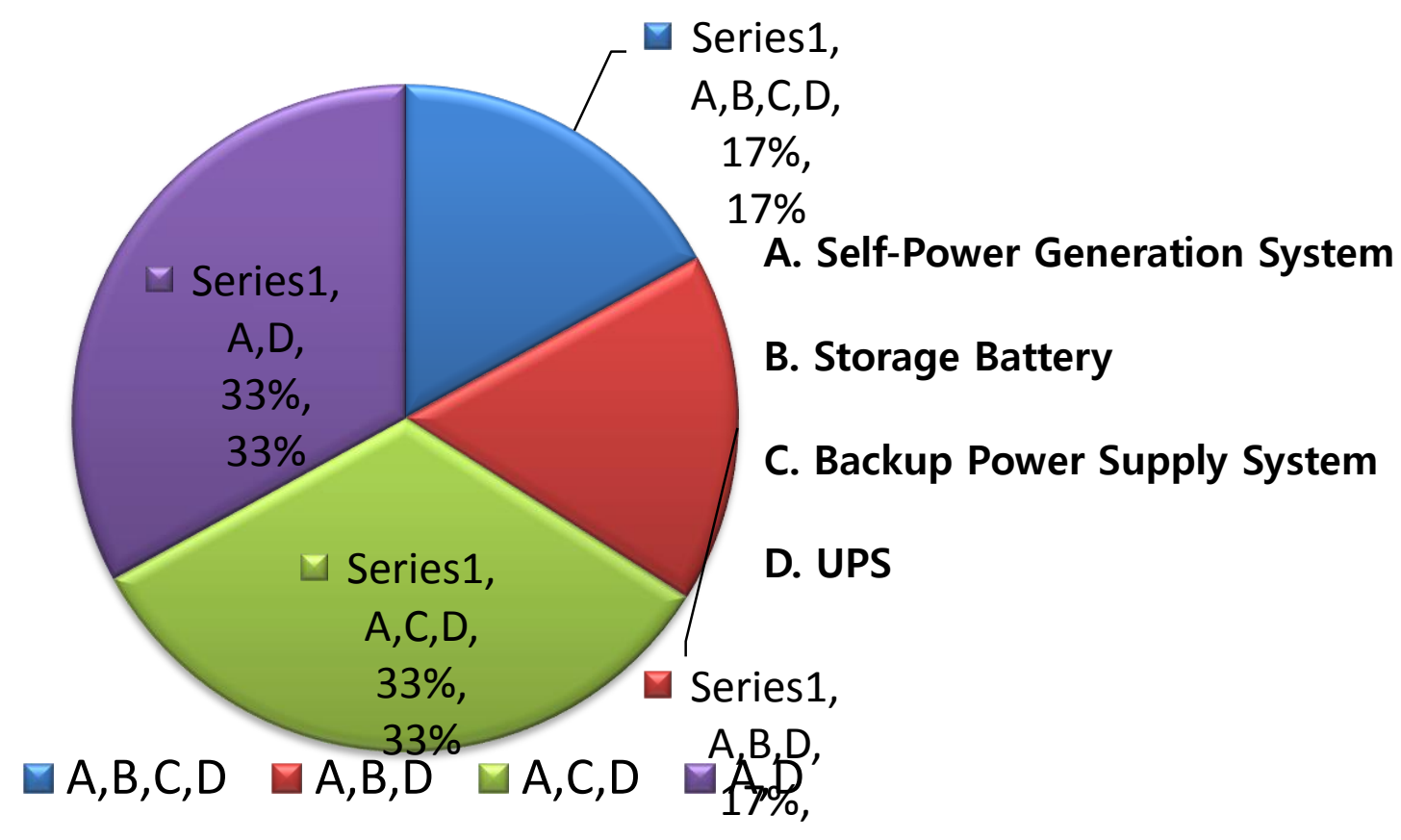

Figure 4. Installed Emergency Power System in Investigated Hospitals

While estimating the running time of emergency power system based on the oil reserves at the hospitals, some of the hospitals surveyed were found to have failed to meet the legal requirement for the operation time. With backup power supply systems, continuous power supply is possible in principle. However, the "emergency" postulated in this study refers to a situation characterized by the difficulty in supplying power due to technical problems at KEPCO or a massive power outage caused by large-scale civic disasters [9]. Hence, for the purpose of this study, it was assumed that the power supply through backup systems is not feasible.

When calculated, the mean operation time of all the emergency power systems installed at the surveyed hospitals (excluding their backup power supply systems) was 12.36 hours. This figure is above what is required by the laws. For this number being slightly above the legally required level, the time would not be enough considering a period of power-grid recovery in case of power outages caused by massive disasters.

Results of the pilot study, on the other hand, revealed that the preferred duration of emergency power supply is $50.7 \mathrm{hrs}$. and that the number identified through surveys in Japan is $120 \mathrm{hrs}$. In the Republic of Korea, where no equivalent massive urban catastrophes have been experienced yet, the preferred durations differ significantly from the Japanese preference. However, considering the global trends where disasters are becoming more frequent, Korea, too, needs to be prepared, using the Japanese standard as a relatively reliable source for disaster preparedness since Japan is susceptible to frequent disasters including earthquakes. 
There are a number of high-priority buildings required to sustain urban functioning; hospitals in particular play a decisive role in saving lives when struck by power supply shortage. Hence, it is imperative that the emergency power supply units in hospitals be expanded in being prepared against disasters that may strike cities anytime anywhere.

\subsection{Analysis of Electrical Load at General Hospitals Surveyed}

The reason why the electrical load at the surveyed hospitals was examined is because an optimal power supply required during emergency and the ways to supply power can be proposed by understanding the energy-consumption characteristics of hospitals (i.e., special-purpose buildings) under normal circumstances. In order to identify the conditions under which emergency power supply systems can be operated efficiently during emergency, the amount of energy consumed in the surveyed hospital buildings was investigated, and the investigation was followed by a multi-faceted analysis of the electrical load models of the hospitals.

One of the more effective power supply options during emergencies is the distributed energy supply systems. In cases where the centralized energy supply system fails to deliver during emergencies, the distributed system can contribute to stabilizing the energy supply to cities. This system's capability to achieve a good balance between buildings with different load modeling characteristics has particularly beneficial effects in terms of utilizing the system's power facilities and achieving energy efficiency.

This study aimed to make it possible for distributed energy system designers to use the model as their guidelines, and in serving that purpose, the study collected energy consumption data from the target area and analyzed the hospitals' power load models from various angles.

The monthly power consumptions at the hospitals from 2010 and 2012 were divided by the total floor area of the hospitals to obtain the estimated amount of power consumption per unit area. Figure 5 shows that the per-unit-area power consumption taking seasonal conditions into consideration was greater in summer when air conditioner overloads occur than winter when heater overloads occur more frequently. In spring and autumn when the air conditioner and heater overloads are relatively less frequent, the power consumption was found to be low.

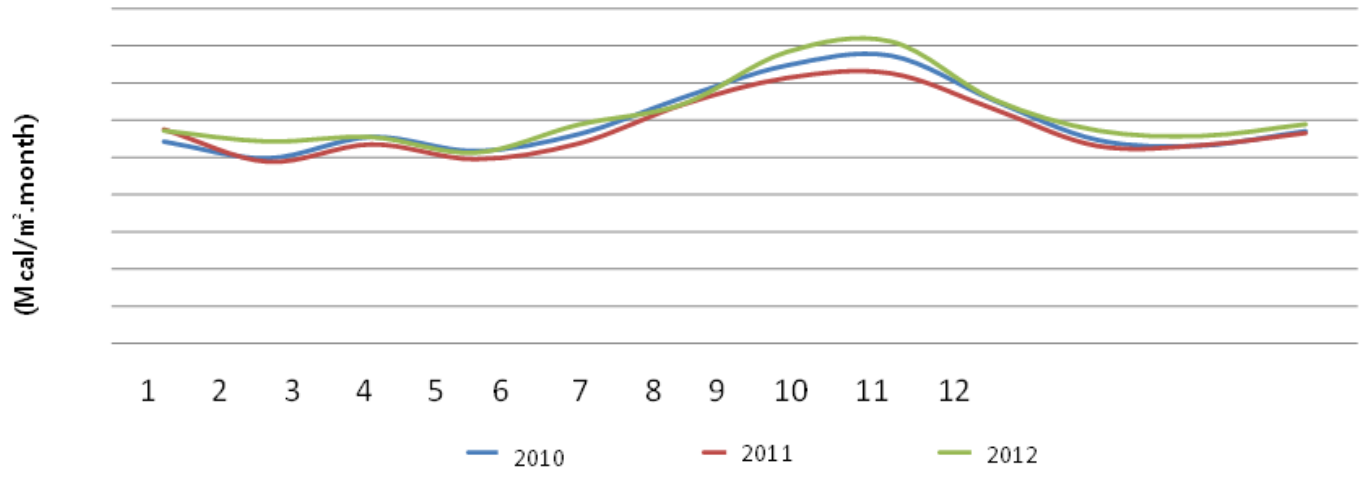

Figure 5. Yearly, Monthly Patterns of Electrical Load

Figure 6 presents graphs by dividing the daily power consumption for 2012 at hospitals by their total floor area, thus obtaining the per unit-area daily power consumption at the hospital. The graphs show the regularity or pattern that occurs on a 
weekly basis. The results showed that the consumption during Saturdays and Sundays was smaller compared with the consumption during weekdays and that the deviation between weekdays and weekends was fairly large.



Figure 6. Dayly Patterns of Electrical Load

Figure 7 summarizes the per unit-area and time-specific power consumption in graphs. The numbers were obtained for the year 2012, a leap year and hence 366 days, by dividing the power consumption in each of the 8784 hours ( 24 hrs. x 366 days) by the hospital's total floor area. As in the other graphs examined earlier, this graph data also showed a seasonal pattern and a regularity occurring on a weekly basis. Specifically, a peak was observed at 10 AM regardless of which season it was; additionally, in summer, another peak was observed at around 3 PM.

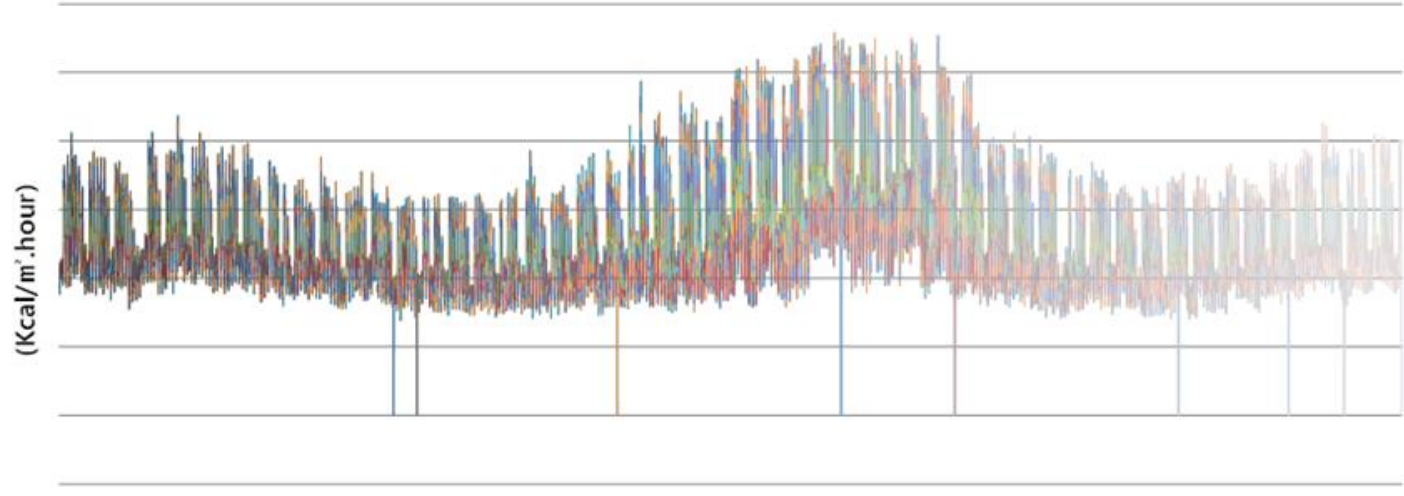

Figure 7. Yearly, Monthly Patterns of Electrical Load

Surveys of the hospital's power load modeling confirmed the seasonal pattern and weekly regularity and the variance, too, was found to be large. 


\subsection{Strategies for Securing Energy at Hospitals during Emergencies}

4.3.1. Distributed Energy Supply System: The distributed energy supply system (hereinafter the "DES System") can be a stable source of power supply in cases where emergencies cause power shortage. The DES System is defined as "the modularized power generation system or grid system located near the end users which can supply a specified amount of electricity or heat to the residential areas or city districts" in DOE1. EPRI2, on the other hand, defines the System as "a small-scale power generation facility/system (no greater than $30 \mathrm{MW}$ ) located at or near where the demand lies, which system is connected either to the existing power grid or is operated independently to economically supply electricity or heat to the satisfaction of consumers"

At present, the global trends in energy consumption at national levels are such that the countries' reliance on centralized energy supply systems is diminishing, whereas their dependence on independent DES System is on the rise. The System is believed to be able to offset the problems caused possibly caused by overloads in centralized energy supply system. The System can also allegedly play a role in ensuring stable power supply during emergencies and the resulting massive power shortages.

4.3.2. Commercialization of Independent Power Generation System: Independent power generation facilities for internal uses at hospitals are required by law to be subject to commissioning once every two years. Under normal circumstances, the majority of such facilities have no operation records except for the ones due to commissioning. This infrequent use raises a question about the reliability of the facilities.

Moreover, expanding the facilities to achieve improvement in their capacity and operation duration will lead to increase in area occupied by the facilities as well as to increase in costs. One effective way to improve upon these problems is utilize the facilities as a resource in peak load management efforts. This model proposes that the reliability of these facilities be increased by utilizing them more under normal conditions, that a more stable management be made possible, and that economic gains be achieved by utilizing them as a peak load management tool.

The Korean government has implemented various measures to help overcome power supply crisis situations, and in the meantime it has implemented policies to reduce overloads in peak hours. For instance, a selective peak rate system was introduced which imposed premium rates three to five times the rates during non-peak hours. Additionally, businesses were advised to stop operations at their factories during peak hours and to request reimbursements from the government to make up for the losses therefrom.

Using independent power generation facilities as a tool to manage peak-hour loads, on the other hand, can offer financial benefits in addition to the above-said encouragement by the government. The proposed option is also effective in increasing the reliability of the facilities under normal circumstances which will otherwise have no opportunities to operate except for during commissioning.

At present, however, no policies are in place to aggressively promote this model, hence it cannot be put to use right away. That its usability can only come from the government's policy support is its limitations. 


\section{Conclusion}

Consumption of energy is on the rise year after year all around the globe. In cities where energy demands are particularly high, high-priority buildings are found everywhere whose functioning must absolutely be maintained. In the Republic of Korea, the majority of its cities are the recipients of energy supply through centralized supply systems using fossil fuel-burning or nuclear power generation facilities. Hence, it would be difficult for their buildings to independently solve energy crisis problems during emergencies or disaster/catastrophe situations.

Major cities are characterized by seriously high energy concentration compared with building concentration and as such, damages or breakage in high-priority buildings in cities which play an integral role in sustaining cities could be such that they can reach astronomical proportions. Particularly, situations preventing energy supply from reaching cities for a certain period of time can lead to additional damages to the cities which can be so damaging that they can shut down the functioning of cities. Therefore, an appropriate mechanism should be proposed to categorize the functions of highpriority buildings and asses their importance, thus contributing at least to the minimal maintenance of the functioning of cities.

This study focused on hospital buildings/structures in that they are among the high-priority buildings and they deal with saving lives. The study also classified hospital size (scale) and type and selected general hospitals as its focal point, followed by studying strategies for securing energy supply to maintain the functioning of hospitals during.

Summary of this study is as follows:

(1) According to the previous studies on the importance of civic buildings during emergency, hospitals were found to be the most important (except for fire station and police station). As for buildings, power systems were rated the most important facilities.

(2) The mean operation time of the surveyed hospitals' emergency power was calculated as 12.36 hours, which is greater than the legally required. This figure, however, is significantly lower than 50.7 hours which was proposed by other Korean studies or 120 hours, the corresponding figure from Japan.

(3) Analysis of the general hospitals' energy consumption revealed that more power was consumed in summer, winter, spring and autumn, in this order, with summer showing the highest power consumption and autumn the lowest power consumption. According to the analysis of time-specific power consumption, the largest power consumption occurred during outpatient service hours in normal weekdays.

(4) The distributed energy supply system ("DES System") has been found to be extremely effective in maintaining the functioning of high-priority buildings during emergencies. With this DES System in place, creating a good balance between buildings characterized by different load models can lead to economic gains, as the System is installed and maintained. At present, independent power generation facilities are being operated only during commissioning, but utilizing them under normal conditions will increase the reliability of emergency power supply. Moreover, utilizing the facilities as a tool to manage peak-hour loads will possibly generate financial gains as well.

Results of this study offer opportunities to draw attention to the supply of emergency energy to the high-priority buildings which play a crucial role in sustaining city functioning during emergencies and to enable systematic securing of energy supply. The results can be an especially effective strategy for the City of Daegu, as it strives to ensure energy security that 
will not be out of line with minimal living, life, and code of conduct during emergencies and to actively cope with global climate changes.

\section{Acknowledgements}

This work was supported by the National Research Foundation of Korea grant funded by the Korea government(MEST) (NRF-2010-0029455) and the Daegu Green Environmental Center Grant Funded(No.13-1-90-94-05).

\section{References}

[1] P. Hwa-chun and J. Mo, "Comparison of Energy load Characteristics of Hotels, Hospitals and Business Buildings", Facilities Engineering, vol. 21, no. 10, (2009).

[2] N. Gyeong-mok, "Strategies to Secure Energy to Maintain the Functioning of Important Buildings in Large Cities During Emergency”, Master's Thesis, Kyungpook National University, (2011).

[3] K. Seon-ho, "Investigation and analysis of emergency generating systems to maintain the functioning of communication facilities during emergency", Master's Thesis, Kyungpook National University, (2011).

[4] Kim Jang-gyeong, Installation standards for large hospitals' backup power systems, Lighting and Electrical Facilities Society Papers, (1997).

[5] Kim Min-ju, Nam Gyeong-mok \& Hong Won-hwa, "A Study on the Calculation of Optimal Capacity of Emergency Power Systems in Important Civic Buildings, Korean Association of Environmentally Friendly Facilities Conference, (2012).

[6] K. Hyeon-mu, "A baseline Study on the Evaluation of Reliability of Local Power Systems Against Natural Disasters", Power Technology Abstracts, (2004).

[7] K. Ju-Young, H. Won-Hwa, C. Seung-Yeon, "A Study on the Characteristics of Energy-Consumption and Energy Consumption Unit of Mass General Hospitals in Daegu Metropolitan City”, Journal of Architectural Institute of Korea, vol. 22, no.11, (2006).

[8] H. Jun-Ho, L. Yong-ho, C. Young-Hum, H. Jung-Ha, "A Study on the Planning of Hybrid Renewable Energy Systems Optimization Apply in the General Hospital Building”, International Journal of Air-Conditioning and Refrigeration Engineering, Proceedings of the IJACR2013 Summer Annual Conference, (2013).

[9] Y. Si-Wan, K. Soo-Hyun, C. Young-Hum, J. Jae-Hun and K. Yong-Shik, An analysis of Energy Consumption of a large hospital building with GSHP system, Proceeding of annual conference of the architectural institute of Korea, (2012).

[10] Choi M.S, Cho K.S. Shin J.R., Applicability of Emergency Back-up Generators for Peak Shaving Resources, Korean Institute of Electrical Engineers PES, Proceedings of Autumn Annual Conference, p.240-242, (2007).

[11] American Society of Heating Refrigeration and Air Conditioning Engineers, 2009 ASHRAE Handbook Fundamentals, (2009).

[12] EM-DAT, “The OFDA/CRED International Disaster Database”, University Catholique de Louvain, Brussels, Belgium, Data version: vol. 1, no. 8, (2009).

\section{Author}



\section{Ji-Ae, Lee}

Ph.D Student

School of Architectural, Civil, Environmental and Energy Engineering Kyungpook National University, Daegu, Republic of Korea ize0304@naver.com 